\title{
Oligotrophication of a large, deep lake alters food quantity and quality constraints at the primary producer-consumer interface
}

\author{
Melanie Hartwich, Dominik Martin-Creuzburg, Karl-Otto Rothhaupt and Alexander Wacker
}

M. Hartwich (melanie. hartwich@uni-potsdam.de) and A. Wacker, Dept of Theoretical Aquatic Ecology, Inst. of Biochemistry and Biology, Univ. of Potsdam, Am Neuen Palais 10, DE-14469 Potsdam, Germany. - D. Martin-Creuzburg and K.-O. Rothhaupt, Limnological Inst., Univ. of Constance, Mainaustrasse 252, DE-78464 Konstanz, Germany.

\begin{abstract}
To assess nutritional consequences associated with lake oligotrophication for aquatic consumers, we analyzed the elemental and biochemical composition of natural seston and concomitantly conducted laboratory growth experiments in which the freshwater key herbivore Daphnia was raised on natural seston of the nowadays (2008) oligotrophic Lake Constance throughout an annual cycle. Food quality mediated constraints on Daphnia performance were assessed by comparing somatic growth rates with seston characteristics (multiple regression analysis) and by manipulating the elemental and biochemical composition of natural seston experimentally (nutrient supplementation). Results were compared to similar experiments carried out previously (1997) during a mesotrophic phase of the lake. In the oligotrophic phase, particulate carbon and phosphorus concentrations were lower, fatty acid concentrations were higher, and the taxonomic composition of phytoplankton was less diverse, with a more diatom- and cryptophytes-dominated community, compared to the previous mesotrophic phase. Multiple regression analysis indicated a shift from a simultaneous limitation by food quantity (in terms of carbon) and quality (i.e. $\alpha$-linolenic acid) during the mesotrophic phase to a complex multiple nutrient limitation mediated by food quantity, phosphorus, and omega-3 fatty acids in the following oligotrophic phase. The concomitant supplementation experiments also revealed seasonal changes in multiple resource limitations, i.e. the prevalent limitation by food quantity was accompanied by a simultaneous limitation by either phosphorus or omega- 3 fatty acids, and thus confirmed and complemented the multiple regression approach. Our results indicate that seasonal and annual changes in nutrient availabilities can create complex co-limitation scenarios consumers have to cope with, which consequently may also affect the efficiency of energy transfer in food webs.
\end{abstract}

In the 20th century, many European lakes suffered from eutrophication caused by high external nutrient inputs. This resulted in drastic changes of food web processes (Jeppesen et al. 2005). In the last decades though, many efforts have been made to remediate the natural (meso-) oligotrophic state of such lakes, mainly via reduction of the phosphorus load (Mehner et al. 2002). Decreasing phosphorus load can lead to 1) a reduced phytoplankton biomass, 2) an increase of seston C:P ratios and 3) an altered taxonomic composition of phytoplankton (Lampert and Sommer 1997, Jeppesen et al. 2005, Sterner et al. 2008). These changes have consequences for primary consumers, such as the freshwater key herbivore Daphnia, which significantly transfers carbon and nutrient to higher trophic levels in many lakes (Sterner and Hessen 1994). The reduced phosphorus availability leads to declining phytoplankton biomass (oligotrophication; Anneville et al. 2005) and consequently may indirectly force herbivore growth into food quantity limitation (Hessen and Anderson 2008).

Daphnia growth also depends on the supply of mineral nutrients, especially phosphorus, because growth is linked to the protein synthesis rate and thus to the concentration of phosphorus-rich ribosomal RNA (Elser et al. 2003). In oligotrophic lakes usually high seston C:P ratios are observed (Elser et al. 2002, Hessen 2006, Sterner et al. 2008), which can lead to insufficient phosphorus supply for consumers (Sterner et al. 1993, Elser et al. 2001). The molar C:P threshold at which Daphnia growth becomes limiting was estimated to be -300 (Olsen et al. 1986, Urabe and Watanabe 1992, Brett et al. 2000), suggesting that at seston C:P ratios $<300$ phosphorus should not be limiting.

Additionally, food quality is a matter of supply with essential biochemicals, such as polyunsaturated fatty acids (PUFAs), of which alpha-linolenic and linoleic acid cannot be synthesized de novo in most animals (Beenakkers et al. 1985). The latter two fatty acids serve as precursors for more long-chain PUFAs, and Daphnia among others can carry out this conversion only at very low rates. In several laboratory studies, PUFAs, especially eicosapentaenoic acid (EPA), have been found to constrain Daphnia growth (Von Elert 2002, Ravet et al. 2003). Moreover, field studies, covering hypertrophic to oligo-mesotrophic lakes and different Daphnia species, suggested that PUFA limitation 
can occur in lakes (Müller-Navarra 1995, Park et al. 2003, Gladyshev et al. 2006). The fatty acid composition of natural seston is largely determined by the phytoplankton taxonomic composition, which in turn depends on the trophic state of a lake (Anneville et al. 2005). During oligotrophication, mixotrophic algae (mostly cryptophytes) and diatoms usually gain in importance while the proportion of cyanobacteria usually decreases (Anneville et al. 2005, Dokulil and Teubner 2005). Regarding the PUFA content, the highest quality algae are diatoms and cryptophytes, followed by chlorophytes, while cyanobacteria are the lowest quality algae (Müller-Navarra et al. 2000, Kainz et al. 2009). This implies a higher risk of zooplankton to be limited by food quality when phytoplankton is not dominated by diatoms or cryptophytes (Brett et al. 2000).

In more oligotrophic lakes, phytoplankton quantity and quality in terms of C:P ratio can be insufficient for zooplankton (Rellstab et al. 2007). In low food quantity environments increasing proportions of carbon are used for basal metabolism and not for production (Sterner 1997). Therefore, animals become severely limited by food quantity, which is associated with a decreasing relevance of food quality constraints (Hessen 1990, Sterner 1997). Nevertheless, at low food quantity the fitness of consumers can be severely affected by food quality (Boersma et al. 2001, Boersma and Kreutzer 2002, Acharya et al. 2004) resulting in a simultaneous limitation by carbon and other potentially limiting nutrients.

The changes of phytoplankton biomass, C:P ratios and taxonomic composition associated with oligotrophication will presumably also result in changing nutrient limitations an herbivore has to cope with. Such a situation might occur in a lake that changes from eutrophic to oligotrophic conditions, such as Lake Constance (Stich and Brinker 2010). In the mesotrophic phase of Lake Constance (1997), results from growth experiments with Daphnia galeata indicated that the content of $\alpha$-linolenic acid (ALA) of lake seston was the limiting factor for Dapbnia growth (Wacker and Von Elert 2001). Since Lake Constance meanwhile changed to a clearly oligotrophic state we investigated if the low availability of ALA remained as the predominant food quality constraint for Daphnia, or if a reduced phytoplankton biomass and/or more unfavorable seston C:P ratios have replaced ALA as main limiting nutrient. To test these hypotheses, we conducted growth experiments after oligotrophication throughout 2008 , in which $D$. galeata was fed pure seston. In a first approach we followed a multiple regression approach using Akaike's model selection criterion (corrected Akaike's information criterion) to identify the relative importance of seston components for Daphnia growth rates, and compared the results with data from experiments during oligotrophication in 1997 (Wacker and Von Elert 2001). In a second approach, to consider that seasonal changes in phytoplankton taxonomic (Sommer 1989) and biochemical composition (Thompson et al. 1990) may lead to changing nutrient limitations during the annual cycle, we conducted laboratory experiments in parallel to test putative limitations at distinct dates of the season in a straightforward manner, i.e. by supplementing natural seston with potentially lacking compounds.

\section{Methods}

Lake Constance $\left(47^{\circ} 40^{\prime} \mathrm{N}, 9^{\circ} 20^{\prime} \mathrm{E}\right)$ is a large, deep, warmmonomictic pre-alpine lake with a surface area of $473 \mathrm{~km}^{2}$, an average depth of $100 \mathrm{~m}$ and a maximal depth of $254 \mathrm{~m}$. Between 1960 and 1980, the lake experienced strong eutrophication. The total phosphorus concentration during the spring circulation increased from $<10 \mu \mathrm{g}^{-1}$ to a maximum of $87 \mu \mathrm{g} \mathrm{I}^{-1}$ in 1979 . Since then Lake Constance underwent intensive oligotrophication, and returned to its natural state of an oligotrophic lake. The total phosphorus concentration during spring circulation of Lake Constance was $18 \mu \mathrm{g} \mathrm{I}^{-1}$ in 1997 and further decreased to $<8 \mu \mathrm{g} \mathrm{t}^{-1}$ in 2008 (Stich and Brinker 2010).

The sampling site with a depth of $60 \mathrm{~m}$ was located in the northwestern part of the lake ('Überlinger See'), at the same site as in Wacker and Von Elert (2001). From April to October 2008, 13 experiments were performed with water from the lake containing seston as food for Daphnia galeata. Water was collected daily with a Ruttner Sampler from $6 \mathrm{~m}$ depth and filtrated through gauze with a mesh size of $30 \mu \mathrm{m}$ to approximately obtain the edible food size of D. galeata (Burns 1968). The sampling depth of $6 \mathrm{~m}$ was chosen because $D$. galeata is usually located at this depth and performs no diurnal vertical migration (Stich and Lampert 1981).

\section{Seston analysis}

Filters for determination of carbon, phosphorus and fatty acids were prepared daily during the growth experiments. For determination of particulate organic carbon (POC), seston $(<30 \mu \mathrm{m})$ was filtered onto precombusted glass fibre filters (Whatman GF/F, $25 \mathrm{~mm}$ diameter) and analyzed using an NCS-analyzer. For determination of particulate phosphorus, lake water was filtered onto acid-rinsed polysulphone filters and afterwards digested with a solution of $10 \%$ potassium peroxodisulfate and $1.5 \%$ sodium hydroxide for $60 \mathrm{~min}$ at $121^{\circ} \mathrm{C}$. Measurements were performed spectrophotometrically using the molybdate-ascorbic acid method (Greenberg et al. 1985).

For analysis of fatty acids, seston was filtered onto precombusted glass fibre filters (Whatman GF/F, $47 \mathrm{~mm}$ diameter), with about $0.5 \mathrm{mg}$ POC per filter. Lipids were extracted and transesterified into fatty acid methyl esters (FAME) and identified and quantified by gas chromatography according to Wacker and Weithoff (2009).

Phytoplankton and bacteria samples were taken weekly during 1997 and 2008 as an integrated sample from 0-8 $\mathrm{m}$ depth. Phytoplankton samples were fixed with Lugol's iodine solution and counted using an inverted light microscope. Bacteria were counted by epifluorescence microscopy after fixation with formaline and DAPI staining (Porter and Feig 1980) under UV light (G $365 \mathrm{~nm}$, FT $395 \mathrm{~nm}, \mathrm{LP}$ $420 \mathrm{~nm}$ ). Cell size of phytoplankton and bacteria were measured and converted into carbon units according to Gaedke (1992).

Daphnia galeata abundance was determined weekly by light microscopy from net samples from $0-140 \mathrm{~m}$ depth. 


\section{Growth experiments}

A clone of D. galeata used in 1997, isolated from Lake Constance (Stich and Lampert 1984, Wacker and Von Elert 2001), was cultivated in $<0.2 \mu \mathrm{m}$ filtrated lake water at $80 \mu \mathrm{mol}$ quanta $\mathrm{m}^{-2} \mathrm{~s}^{-1}$ with the green alga Scenedesmus obliquus (Sammlung für Algenkulturen Göttingen ( $\mathrm{SAG}$ ) 276-3a) as food ( $\left.\mathrm{mg} \mathrm{C}^{-1}\right)$. Scenedesmus obliquus was cultured semi-continuously in Cyano medium (Jüttner et al. 1983) with a dilution rate of $0.25 \mathrm{~d}^{-1}$ at $120 \mu \mathrm{mol}$ quanta $\mathrm{m}^{-2} \mathrm{~s}^{-1}$. Prior to the experiments, mothers were transferred into lake water from the sampling site a few hours before they released their third clutch juveniles, to prevent that newly hatched neonates feed on $S$. obliquus and store nutrients from this laboratory food.

The laboratory experiments ran in triplicate, except for the first and fourth experiment which ran with five replicates, and were performed in glass beakers filled with $200 \mathrm{ml}$ seston and 10 neonates per beaker at $80 \mu \mathrm{mol}$ quanta $\mathrm{m}^{-2} \mathrm{~s}^{-1}$. We conducted two experimental series. In the first, the treatments were: pure lake seston, seston + Synechococcus elongatus (SYN; SAG 89.79; molar C:P ratio $=58 \pm 9)$ and seston + phosphorus. SYN was cultured semi-continuously in Cyano medium (Jüttner et al. 1983) with a dilution rate of $0.25 \mathrm{~d}^{-1}$. This non-toxic cyanobacterium was used to test for carbon limitation of $D$. galeata, because it lacks long-chain PUFAs (Wacker and MartinCreuzburg 2007). Since SYN not only provides carbon, but also phosphorus, we could distinguish between carbon and phosphorus effects using the results of the phosphorus supplementation (Urabe et al. 1997). Nevertheless, it is difficult to distinguish between carbon and phosphorus effects, because the availability of phosphorus for $D$. galeata might differ between the supplementation with SYN and pure phosphorus. If SYN supplementation has a stronger effect on growth than phosphorus supplementation, carbon limitation is likely. In the second experimental series, seston was supplemented with EPA and ALA. Because EPA and ALA were added using liposomes as carriers that consisted of phospholipids and were suspended in phosphate buffer, the control treatment in this case was seston plus liposomes that did not contain EPA or ALA, hereafter called control liposomes. Liposomes were prepared according to Martin-Creuzburg et al. (2008).

Food suspensions were renewed daily with daily collected fresh lake seston $<30 \mu \mathrm{m}$, the beakers were kept at $20 \pm 1^{\circ} \mathrm{C}$ and a light:dark cycle of $16: 8 \mathrm{~h}$. Before the precise measured POC was available, POC concentration of the seston was roughly estimated with respect to daily measured secchi depth which was crucial to estimate the amount of SYN and liposomes that had to be supplemented. SYN was added to lake seston to a final total particulate organic carbon concentration of $1 \mathrm{mg} \mathrm{C} \mathrm{H}^{-1}$. Liposome and phosphorus supplementations also were fitted to the estimated carbon content of the lake water, whereby for $1 \mathrm{mg} \mathrm{C} \mathrm{I}^{-1}$ in the seston $200 \mu \mathrm{l}$ liposomes $\left(0.67 \mu \mathrm{g} \mathrm{P} \mu \mathrm{l}\right.$ liposomes ${ }^{-1}$, $148 \mathrm{ng}$ EPA $\mu 1$ liposomes ${ }^{-1}, 186 \mathrm{ng}$ ALA $\mu$ l liposomes $\left.{ }^{-1}\right)$ or $200 \mu \mathrm{l}$ phosphorus buffer $\left(0.62 \mu \mathrm{g} \mathrm{P} \mu \mathrm{l}\right.$ buffer $\left.^{-1}\right)$ were added. We added phosphorus in an amount that would create eutrophic conditions for the organisms $<30 \mu \mathrm{m}$. Phytoplankton is able to incorporate phosphorus quite fast (Urabe et al. 1997, Plath and Boersma 2001) and phosphorus uptake leads to decreased C:P ratio of the cells (Rothhaupt 1995). After six days, the animals were dried for $24 \mathrm{~h}$ at $60^{\circ} \mathrm{C}$ and the dry mass (mean values of at least five animals) was determined with an electronic balance. Somatic growth rates of $D$. galeata were determined with the equation $g=\left[\ln \left(M_{t}\right)-\ln \left(M_{0}\right)\right] / t$, where $M_{0}$ is the mean individual dry mass at the beginning of the experiment and $M_{t}$ is the mean dry mass of the animals after $t=6 \mathrm{~d}$.

\section{Data processing and statistics}

To compare the data between 2008 and 1997, the annual cycles were subdivided into seasonal phases according to Gaedke et al. (2002). Date and duration of the phases differ between the years probably due to meteorological changes and global warming (Anneville et al. 2004, Seebens et al. 2009). Comparison of seston data for each of the different phases between both years (spring, clear water phase, early summer, late summer, and fall) was done with one-way ANOVA.

Akaike information criterion corrected for small sample sizes (AICc) was used as a model selection criterion to determine the best predictors for growth rates of $D$. galeata in the experiments in 1997 and 2008. An additive model considering the four variables food carbon (mg $\mathrm{C}^{-1}$ ), and relative concentration of phosphorus, EPA and ALA (each in $\mu \mathrm{g} \mathrm{mg} \mathrm{C}^{-1}$ ) in the food was fitted to growth rates of $D$. galeata obtained in 1997 and 2008, respectively. The model was stepwise simplified by removing one or more variables, and the AICc and the Akaike weights for each model were used to determine the best predictors of growth. The sum of Akaike weights was computed for each variable over models that they were included, to assess the relative importance of the single predictors (Burnham and Anderson 1998, Johnson and Omland 2004). Variance inflation factors (VIF) were computed for the best models according to Akaike weights to check for collinearity of the variables in the different models. Carbon, phosphorus, EPA and ALA data were log-transformed. All data met the assumptions of homogeneity of variance and normally distribution of errors.

Growth rates of $D$. galeata obtained on different food treatments in each experiment in 2008 were analyzed using one-way ANOVA followed by Tukey's HSD post hoc test. Thereby each supplementation series was analyzed separately to its respective control treatment. To test for significant effects mediated by the addition of carbon (i.e. supplementation with SYN) and phosphorus, growth rates on seston + SYN and on seston + phosphorus were compared to growth rates on pure seston in each experiment. To test for fatty acid supplementation effects, growth rates on seston + EPA and on seston + ALA were compared with growth rates on seston + control liposomes. All calculations and statistics were performed with the statistic program $\mathrm{R}$ (ver. 2.13.0).

\section{Results}

\section{Lake seston}

The POC concentration of lake seston $<30 \mu \mathrm{m}$ showed a distinct seasonal pattern during and after oligotrophication in the years 1997 and 2008, respectively (Fig. 1a) but with 

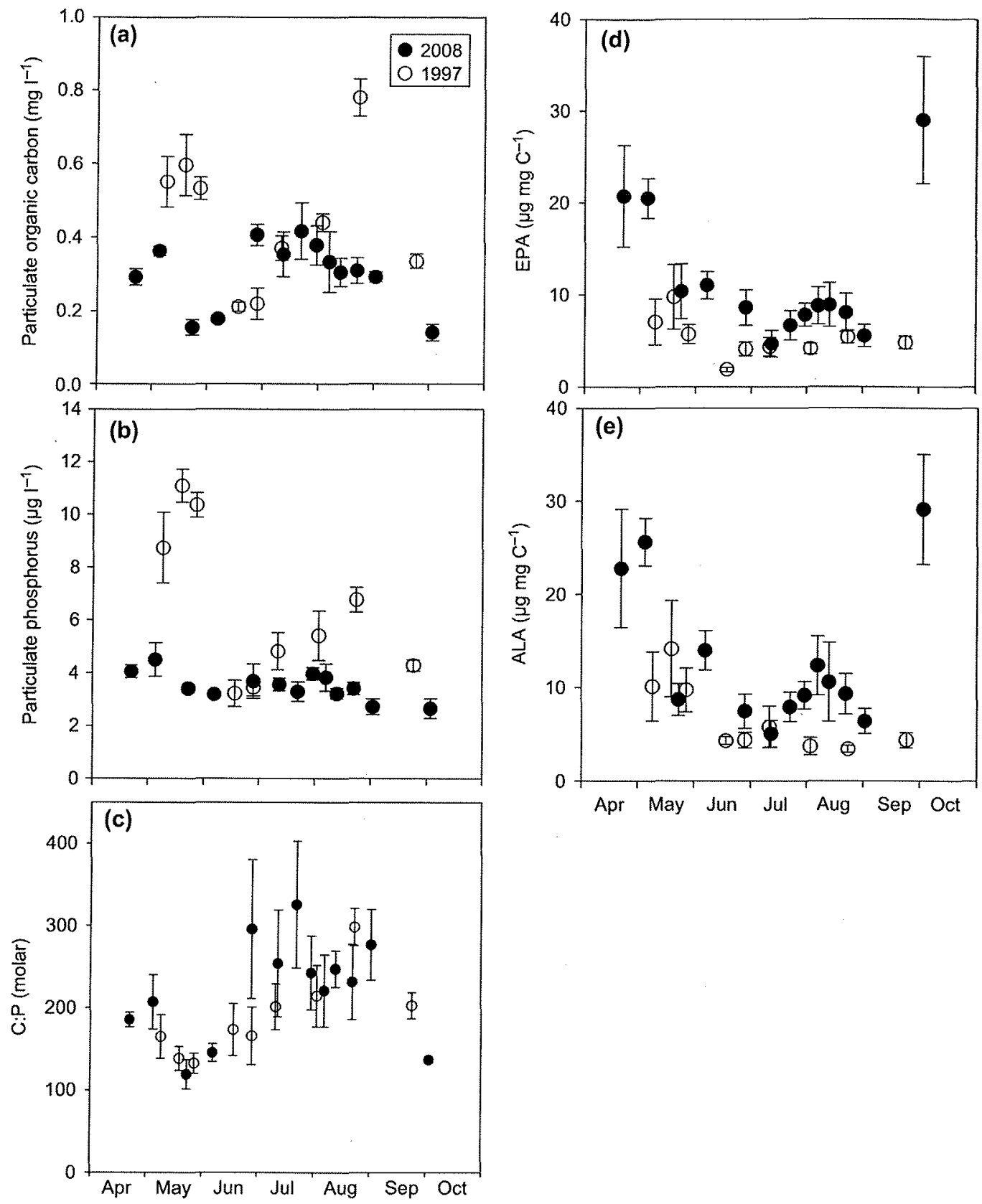

Figure 1. Concentrations of seston parameters of lake water $<30 \mu \mathrm{m}$ in the oligtrophic (2008; filled symbols) and mesotrophic phase (1997; empty symbols). (a) Particulate organic carbon ( $\mathrm{mg} \mathrm{Cl}^{-1}$ ), (b) particulate phosphorus $\left(\mu \mathrm{g} \mathrm{P} \mathrm{l}^{-1}\right.$ ), (c) molar C:P ratio, (d) EPA and (e) ALA ( $\left.\mu \mathrm{g} \mathrm{mg} \mathrm{C}^{-1}\right)$ in lake seston during the growth experiments. Values are means \pm standard deviation from six days and four days with daily measurements during the experiments in 2008 and 1997, respectively. Particulate organic carbon and C:P data for 1997 are redrawn from Wacker and Von Elert (2001).

significantly higher POC concentrations during most of the study period in 2008 compared to 1997 (Table 1) (Wacker and Von Elert 2001). Only during early summer, POC concentrations were similar in both years.

In 2008, the particulate phosphorus concentrations were relatively constant throughout the year (overall mean of $3.5 \pm 0.5 \mu \mathrm{g}^{-1}$ ) and significantly lower than in 1997, except during the clear water phase (Fig. 1b, Table 1).
Contrary, in 1997, the particulate phosphorus concentration showed more seasonal variability.

The C:P ratios of seston $<30 \mu \mathrm{m}$ differed significantly between the years, except for late summer (Fig. Ic). During spring and early summer the C:P ratio was higher in 2008 than in 1997, while during clear water phase and fall it was lower in 2008 (Table 1). The maximum ratios were observed as 325 and 298 in July 2008 and summer 1997, respectively. 
Table 1. Results of analyses of variance (ANOVA) to compare particulate organic carbon $\left(\mathrm{C} ;\left.\mathrm{mg}\right|^{-1}\right)$, particulate phosphorus $\left(\mathrm{P} ; \mu \mathrm{g} \mathrm{|}^{-1}\right), \mathrm{C}: \mathrm{P}$ ratio, $\alpha$-linolenic acid (ALA; $\mu \mathrm{g} \mathrm{mg} \mathrm{C}^{-1}$ ) and eicosapentaenoic acid (EPA; $\mu \mathrm{g} \mathrm{mg} \mathrm{C}^{-1}$ ) in seston $<30 \mu \mathrm{m}$ between 1997 and 2008. Data were compared within the respective seasonal phases (CWP $=$ clear water phase).

\begin{tabular}{|c|c|c|c|c|c|c|c|c|c|c|}
\hline & \multicolumn{2}{|c|}{ Spring } & \multicolumn{2}{|c|}{ CWP } & \multicolumn{2}{|c|}{$\begin{array}{c}\text { Early } \\
\text { summer }\end{array}$} & \multicolumn{2}{|c|}{$\begin{array}{c}\text { Late } \\
\text { summer }\end{array}$} & \multicolumn{2}{|c|}{ Fall } \\
\hline & $\mathrm{F}$ & $p$ & $F$ & $\mathrm{p}$ & $F$ & $\mathrm{p}$ & $F$ & $p$ & $F$ & $p$ \\
\hline C & 109.3 & $* * *$ & 17.8 & 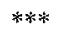 & 0.4 & 0.54 & 54.3 & $* * *$ & 142.4 & $* * *$ \\
\hline $\mathrm{P}$ & 284.3 & $* * *$ & 0.1 & 0.77 & 19.8 & $* * *$ & 100.9 & $* * *$ & 46.8 & $* *$ \\
\hline $\mathrm{C}: \mathrm{P}$ & 28.4 & $* * *$ & 9.8 & $\ddot{* *}$ & 5.7 & $*$ & 0.3 & 0.62 & 61.3 & $* * *$ \\
\hline$A L A$ & 44.7 & $* * *$ & 35.6 & $* * *$ & 0.8 & 0.39 & 24.3 & $* * *$ & 49.6 & $* * *$ \\
\hline EPA & 73.8 & **** & 76.6 & $* *$ & 3.6 & 0.07 & 13.8 & $* * *$ & 34.6 & $* *$ \\
\hline
\end{tabular}

${ }^{*} \mathrm{p}<0.05 ;{ }^{* *} \mathrm{p}<0.01 ;{ }^{* * *} \mathrm{p}<0.001$.
The concentration of EPA and ALA per unit carbon of seston $<30 \mu \mathrm{m}$ were significantly higher in 2008 than in 1997 (Fig. 1-e). In fall they were even more than six-fold higher, and only during early summer the values were similar (Table 1). In both years these fatty acids were high during spring and decreased to a relatively low level in summer. Only in fall 2008 a subsequent strong increase was observed.

In 1997 and 2008, the spring phytoplankton community $<30 \mu \mathrm{m}$ was dominated by diatoms, while during the clear water phase cryptophytes were the dominant group (Fig. 2a-b). During summer and fall the phytoplankton composition differed between the years. In 2008 phytoplankton was dominated by cryptophytes in late summer and fall, whereas in 1997 in summer phytoplankton composition was more diverse (chrysophytes

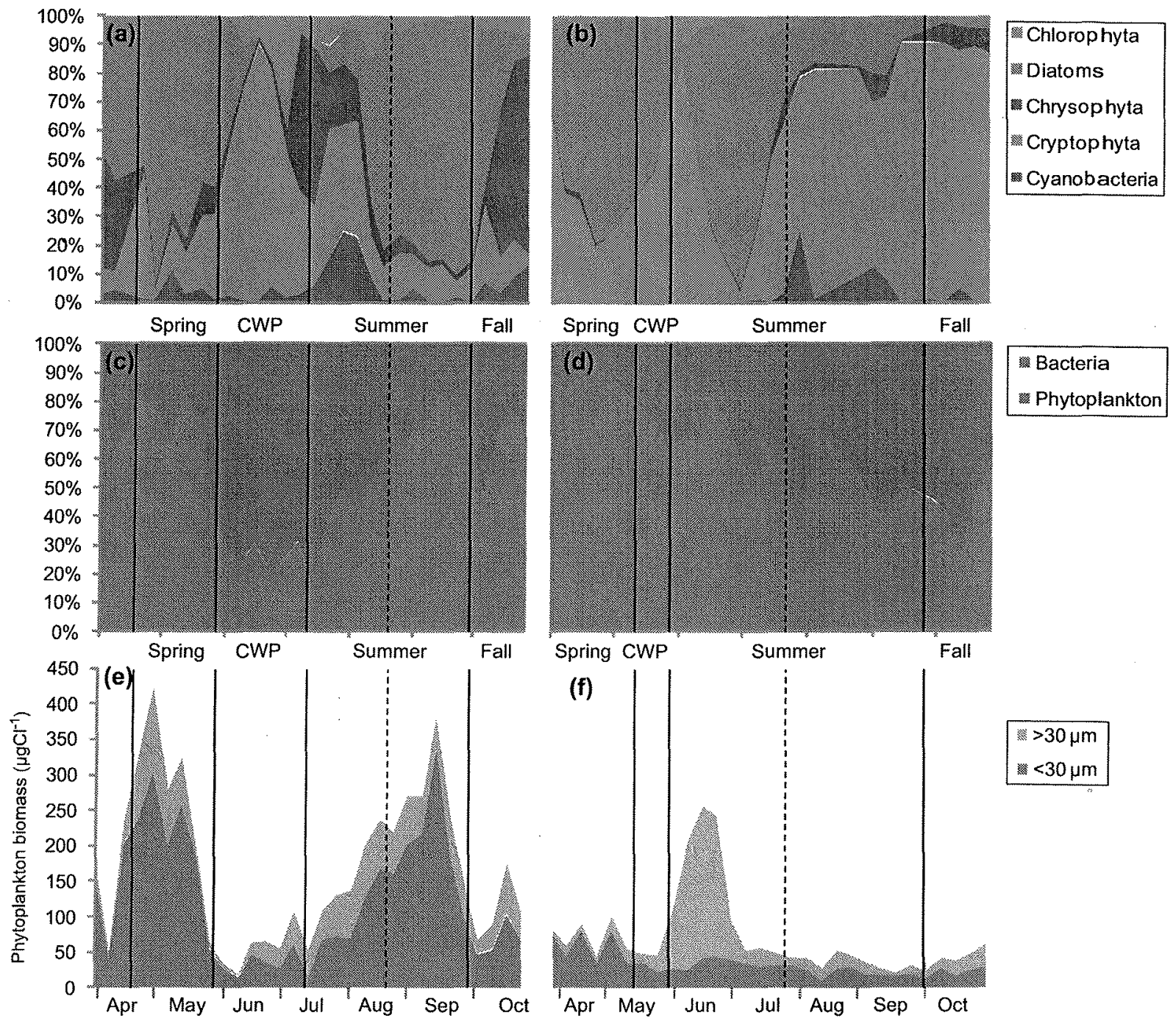

Figure 2. Seasonal changes of the contributions of different phytoplankton groups in 1997 (a) and 2008 (b) to total phytoplankton carbon $<30 \mu \mathrm{m}$, relative contributions of bacteria and phytoplankton in 1997 (c) and 2008 (d) to total carbon (bacteria + phytoplankton $<30 \mu \mathrm{m}$ ), and quantity of total phytoplankton $\left(\mu \mathrm{g} \mathrm{C}^{-1}\right)$ in 1997 (e) and 2008 (f) whereby grey shows the contribution of phytoplankton $>30 \mu \mathrm{m}$ and blue shows the contribution of phytoplankton $<30 \mu \mathrm{m}$ to total phytoplankton biomass. The dotted line divides the phase summer into early and late summer. 
$20-55 \%$, cryptophytes $28-45 \%$, cyanobacteria up to $25 \%$ ); in fall diatoms dominated with up to $88 \%$. Phytoplankton contributed up to $84 \%$ and $92 \%$ (in 1997 and 2008, respectively) to the total carbon of bacteria and phytoplankton (Fig. 2c-d). However, its share continuously decreased over the season to a minimum of $32 \%$ in late summer 2008 and $19 \%$ in the clear water phase 1997 . The proportion of phytoplankton $<30 \mu \mathrm{m}$ to total phytoplankton biomass differed only during summer between the years (1997: $65 \pm 16 \% ; 2008: 50 \pm 19 \% ; \mathrm{F}=5.6, \mathrm{p}<0.05)$.

In $1997, D$. galeata had a maximum of $3.1 \times 10^{5}$ daphnids $\mathrm{m}^{-2}$ during the clear water phase and in 2008 the maximum reached only $5 \%$ of the maximum abundance of $1997\left(1.6 \times 10^{4}\right.$ daphnids $\left.\mathrm{m}^{-2}\right)$. A similar decrease was observed for the mean average abundance of $D$. galeata from spring to fall, which dropped from $3.1 \times 10^{4}$ daphnids $\mathrm{m}^{-2}$ in 1997 to $1.6 \times 10^{3}$ daphnids $\mathrm{m}^{-2}$ in 2008 .

\section{Growth experiments}

In 2008, the growth rates of D. galeata fed pure seston showed a similar pronounced seasonal variability as the POC concentration (Fig. 3) and ranged between $0.27 \pm 0.01 \mathrm{~d}^{-1}$ in spring, $0.08 \pm 0.001 \mathrm{~d}^{-1}$ in the clear water phase and $0.33 \pm 0.05 \mathrm{~d}^{-1}$ in summer.

Model selection using AICc and Akaike weights revealed that out of the four variables carbon and ALA had the highest relative importance and were the best predictors for somatic growth rates of D. galeata in 1997 (Table 2) (Fig. 4). In the best model carbon and ALA showed no collinearity $(\mathrm{VIF}<10)$.

For 2008, four rather similar models were selected as the best models by comparing AlCc values. These four models summed up to 0.75 Akaike weights and comprised all predictors (Table 2). Carbon as predictor for growth rate of $D$. galeata had the highest relative importance, followed by EPA and ALA, while phosphorus was of lowest importance (Fig. 4f). The calculated VIFs in the four best models were $<10$, indicating the absence of collinearity.

Compared to growth on pure lake seston, supplementation of seston with SYN had a significantly positive effect on growth rates of D. galeata in nearly all experiments (Fig. 5a,

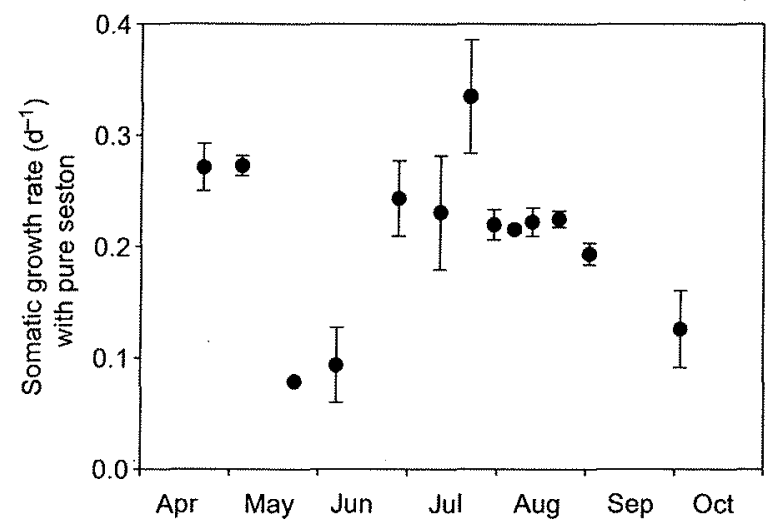

Figure 3. Somatic growth rates $\left(\mathrm{d}^{-1}\right)$ of $D$. galeata fed unsupplemented lake seston $<30 \mu \mathrm{m}$ from April to October 2008. Error bars show standard deviation of growth rates $(n=3$, except experiments 1 and $4 n=5$, experiment $3 n=2$ ).
Table 2. Results of model selection using the variables particulate carbon (C), particulate phosphorus (P), EPA and ALA ( $\left.\mu \mathrm{g} \mathrm{mg} \mathrm{C}^{-1}\right)$ as predictors for $D$. galeata growth rate $(\mathrm{g})$ in 1997 and 2008. Shown are the 5 best models according to Akaike's information criterion (AICC) and the full model including all predictors. The models with the lowest $\mathrm{AICC}$ and a cumulative sum of 0.75 Akaike weights (AICW) are highlighted.

\begin{tabular}{|c|c|c|c|}
\hline Year & Model & $\mathrm{AlCc}$ & $\mathrm{AlCw}$ \\
\hline \multirow[t]{6}{*}{1997} & $g-1+C+A L A$ & -20.67 & 0.87 \\
\hline & $g-1+P+A L A$ & -15.41 & 0.06 \\
\hline & $g-1+A L A$ & -12.98 & 0.02 \\
\hline & $g \sim 1+C+P$ & -12.93 & 0.02 \\
\hline & $g \sim 1+E P A$ & -12.07 & 0.01 \\
\hline & $g-1+C+P+E P A+A L A$ & 14.83 & 0.00 \\
\hline \multirow[t]{6}{*}{2008} & $g-1+C+E P A$ & -44.69 & 0.30 \\
\hline & $g \sim 1+C+A L A$ & -44.24 & 0.24 \\
\hline & $g \sim 1+C$ & -43.32 & 0.15 \\
\hline & $g-1+C+P+E P A$ & -42.39 & 0.09 \\
\hline & $g-1+P+E P A$ & -41.75 & 0.07 \\
\hline & $g \sim 1+C+P+E P A+A L A$ & -34.97 & 0.00 \\
\hline
\end{tabular}

Table 3), indicating a food quantity limitation of D. galeata growth almost during the whole year. A positive effect of phosphorus supplementation was evident only in two experiments: in the second experiment during the spring bloom and in one experiment in late August (Fig. 5a). With the exception of the fifth experiment (June), growth rates obtained on seston $+S Y N$ and seston + phosphorus were significantly different $(\mathrm{p}<0.05$, Table 3$)$.

Positive effects of EPA supplementation were obtained during late summer, i.e. in four experiments in August and early September the growth of D. galeata was enhanced when seston was supplemented with EPA containing liposomes (Fig. 5b). At the same time, the addition of SYN also increased the growth rate of Daphnia. In contrast, supplementation with ALA-containing liposomes never had a significant positive effect on growth rates compared to growth rates obtained on seston supplemented with control liposomes (Fig. 5b). Growth rates were significantly higher in the treatments seston + EPA than seston + ALA during experiment 9 and $12(p<0.05)$ and did not differ in the other experiments.

\section{Discussion}

We show here that oligotrophication of a large pre-alpine lake (Lake Constance) is associated with reduced phytoplankton biomass and changes in its taxonomic composition, and consequently with changing nutrient limitations herbivorous consumers, such as Daphnia, have to cope with.

Due to the ongoing oligotrophication process in Lake Constance with decreasing SRP concentrations, we expected to find a strong increase in seston C:P ratios (Hessen 2006) and/or a decrease in phytoplankton biomass (Van Donk et al. 2008). Interestingly, similar decreases in seston carbon and phosphorus over the years led to C:P ratios in 2008 that were still $<300$ most of the year, as in 1997, and therefore in a range where phosphorus should not limit Daphnia growth. One explanation for unchanged $\mathrm{C}: \mathrm{P}$ ratios of seston might be the high mixing depth in Lake Constance enabling 

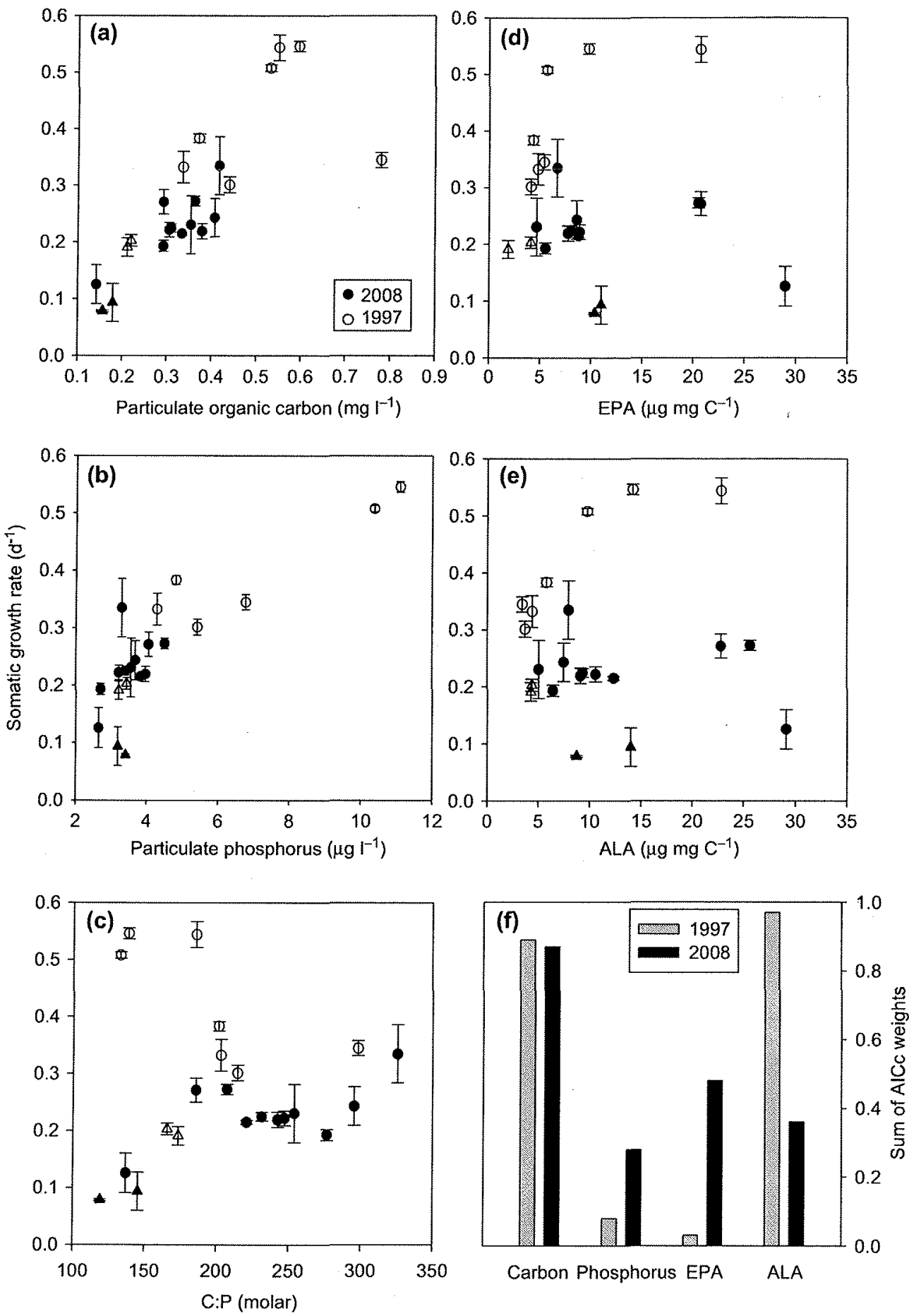

Figure 4. Correlation of somatic growth rates of $D$. galeata on unsupplemented seston with (a) particulate organic carbon content (mg C $1^{-1}$ ), (b) particulare phosphorus ( $\mu \mathrm{g} \mathrm{P} \mathrm{I}^{-1}$ ), (c) molar C:P ratio, (d) EPA and (e) AlA concentration ( $\mu \mathrm{g} \mathrm{mg} \mathrm{C}^{-1}$ ) of the seston 2008 (filled symbols) and 1997 (empty symbols). Triangles indicate data during clear water phase. Error bars show standard deviation. (f) Relative importance of the variables carbon, phosphorus, EPA and ALA calculated by the sum of Akaike weights of all models they were included.

phytoplankton organisms to utilize SRP which usually has a higher concentration in deeper water layers. Transport of phytoplankton into deeper layers may also result in lightlimited growth, which would partly explain the decrease of phytoplankton biomass. Second, the food of Daphnia also comprises mixo- and heterotrophic microorganisms, including phosphorus-rich bacteria (Kamjunke et al. 1999). Probably the quantitative relevance of these organisms 

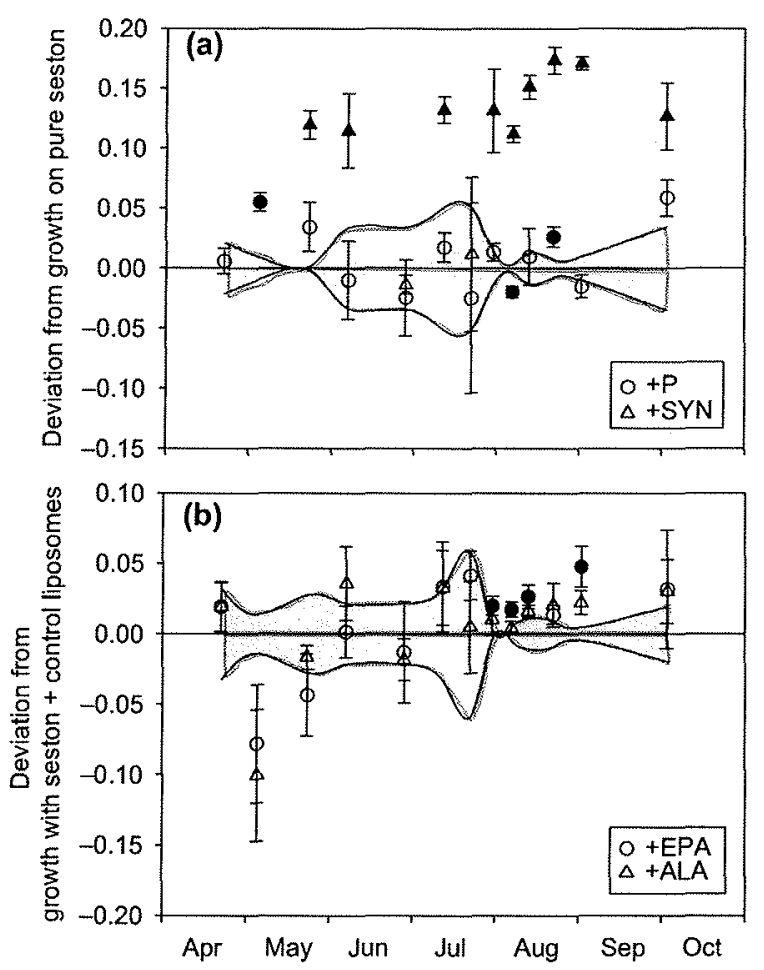

Figure 5. Phosphorus (P) and Synechococcus (SYN) supplementation effects in relation to growth rate with pure seston (a). To visualize the effects of supplementation with SYN and phosphorus, mean growth rate of control treatment (pure seston) was set to zero for every experiment and deviations of growth rates in supplemented treatments are shown. Symbols are filled when growth rates with supplementation were significantly different from growth rates with pure seston (Tukey post hoctest after ANOVA, $p<0.05$ ). (b) Effects of EPA- and ALA-supplementation relative to growth with pure seston supplemented with control liposomes. To visualize the effects of supplementation with fatty acids, the mean growth rate of the control treatment (supplementation with control liposomes) was set to zero for every experiment and deviations of growth rates in fatty acid treatments are shown. Filled symbols show significantly different growth rates compared to growth on seston supplemented with control liposomes $(p<0.05)$. The gray area between the black lines shows the standard deviation of (a) growth with pure seston and (b) growth with seston supplemented with control liposomes. Error bars show standard deviation of growth rates $(n=3$, except experiments 1 and $4 n=5)$.

increased during oligotrophication, enhancing their function as a transfer-link of nutrients to higher trophic levels (Sherr and Sherr 1988, Vadstein et al. 1993).

The concentration of fatty acids in lake seston was higher in 2008, probably as a result of taxonomic changes of phytoplankton. In 1997, the phytoplankton community was quite diverse, mainly consisting of chrysophytes, cryptophytes and cyanobacteria. In particular, cyanobacteria are known to be of insufficient food quality for Daphnia (DeMott and Müller-Navarra 1997, Martin-Creuzburg et al. 2008). But also chrysophytes, despite a high content of long-chain PUFAs (unpubl.), were occasionally found to be an inadequate food for Daphnia (Leeper and Porter 1995, Katechakis et al. 2005). In 2008, phytoplankton $<30 \mu \mathrm{m}$ was dominated by cryptophytes and diatoms, algae taxa which usually contain high amounts of EPA and ALA (Ahlgren et al. 1990). Higher fatty acid concentrations in the oligorrophic phase of the lake may also be caused by changes in nutrient (phosphorus) availability for algae, which can lead to changes in their fatty acid content (Piepho et al. 2012).

Our hypothesis that food quantity may have become more important as a food quality constraint for $D$. galeata growth in 2008 is supported by the finding that carbon was identified as an important predictor of growth in four out of the five best models - according to Akaike weights and the resulting high relative importance of this vatiable. Carbon limitation was additionally confirmed by the positive effect of SYN supplementations in the growth experiments (Fig. 5a). As expected, D. galeata was carbon limited during the clear water phase and fall, where the carbon content of seston was extremely low with values $<0.2 \mathrm{mg} \mathrm{Cl}^{-1}$. The carbon limitation lasted almost throughout the entire year and fits with the observation that the carbon concentration of seston $<30 \mu \mathrm{m}$ remained mostly below the suggested limiting quantity for $D$. galeata growth of $0.4 \mathrm{mg}$ $\mathrm{C} \mathrm{I}^{-1}$ (Müller-Navarra and Lampert 1996, Gladyshev et al. 2008). Only in two experiments in July with the highest carbon concentrations, carbon supplementation via SYN had no significant effect on the growth rates, i.e. the animals were not quantity limited at this time of the year.

The distinct food quantity limitation of $D$. galeata in the oligotrophic lake may explain long term changes in the abundance of this species. Besides D. galeata, a second species, Daphnia hyalina, coexists in Lake Constance, and $D$. hyalina was the dominant species before the lake underwent eutrophication. During eutrophication $D$. galeata appeared and established in the lake but its biomass declined thereafter during oligotrophication while the biomass of $D$. byalina was only slightly affected (Straile and Geller 1998). The strong carbon limitation of D. galeata we have shown here together with the knowledge that at low food concentration D. galeata is the poorer competitor compared to D. hyalina (Stich and Lampert 1984), can serve as an explanation for the decline in its abundance in now oligotrophic Lake Constance.

The seston C:P ratio slightly exceeded the suggested threshold ratio of $\sim 300$ (Urabe et al. 1997) in only one experiment in June. Thus, phosphorus should not have been the main limiting factor for Daphnia growth, and indeed phosphorus as predictor for growth had the lowest relative importance in our study. Accordingly, we found that only during two experiments, one in spring and one in late August, the supplementation of seston with phosphorus buffer had a significantly positive effect on the growth rate of $D$. galeata. Our method of supplementing phosphorus to lake seston has some restrictions. The proportion of detritus in seston was high, and the phosphorus might have been poorly assimilated by seston organisms. Hence, the supplementation might not have considerably changed the C:P ratio of seston leading to a lack of positive effects in other experiments. We cannot eliminate this uncertainty because C:P was not measured in the experimental beakers after supplementation. Nevertheless, we expect our phosphorus supplementation method as sufficient because in a separate 
Table 3. Results of analyses of variance (ANOVA) for growth rates of D. galeata raised on different food treatments for each experiment (EXP). Carbon and phosphorus effects were analyzed by comparing growth rates on seston supplemented with Synechococcus (SYN) or phosphorus buffer (P) with growth rates on pure seston. For fatty acid effects, growth rates with seston supplemented with EPA and ALA were compared to growth on seston supplemented with control liposomes. Asterisks indicate significant effects after Tukey's HSD post hoc test. During the first two experiments no supplementation with SYN was conducted. DF $<2,6$ are caused by missing replicates.

\begin{tabular}{|c|c|c|c|c|c|c|c|c|c|c|}
\hline \multirow[b]{2}{*}{ EXP } & \multicolumn{5}{|c|}{ Carbon and phosphorus effects } & \multicolumn{5}{|c|}{ EPA and ALA effects } \\
\hline & DF & $\mathrm{F}$ & $\mathrm{p}$ & SYN & $P$ & DF & $F$ & $\mathrm{p}$ & EPA & ALA \\
\hline 1 & 1,8 & 0.32 & 0.587 & 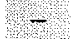 & & 2,11 & 1.03 & 0.389 & & \\
\hline 2 & 1,4 & 63.48 & $<0.01$ & 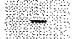 & $* *$ & 2,5 & 6.08 & $<0.05$ & & $\circ$ \\
\hline 3 & 2,4 & 54.52 & $<0.01$ & 1. & & 2,6 & 2.55 & 0.158 & & \\
\hline 4 & 2,9 & 19.91 & $<0.001$ & , & & 2,11 & 3.68 & 0.06 & & \\
\hline 5 & 2,6 & 0.61 & 0.572 & :. & & 2,6 & 0.39 & 0.687 & & \\
\hline 6 & 2,6 & 16.01 & $<0.01$ & (1) & & 2,6 & 1.19 & 0.367 & & \\
\hline 7 & 2,6 & 0.24 & 0.367 & 1) & & 2,5 & 1.12 & 0.395 & & \\
\hline 8 & 2,6 & 32.37 & $<0.001$ & r.t. & & 2,6 & 4.82 & 0.056 & 0 & \\
\hline 9 & 2,6 & 548.94 & $<0.001$ & $x+x$ & $* *$ & 2,6 & 10.03 & $<0.05$ & $*$ & \\
\hline 10 & 2,6 & 77.71 & $<0.001$ & $* *+1$ & & 2,6 & 7.95 & $<0.05$ & * & \\
\hline 11 & 2,6 & 314.20 & $<0.001$ & $x+x$ & $*$ & 2,6 & 2.67 & 0.148 & & \\
\hline 12 & 2,6 & 441.15 & $<0.001$ & $x+x$ & & 2,6 & 16.95 & $<0.01$ & $x *$ & \\
\hline 13 & 2,6 & 16.42 & $<0.01$ & **: & & 2,6 & 1.09 & 0.394 & & \\
\hline
\end{tabular}

${ }^{\circ} p<0.1 ;{ }^{*} p<0.05 ;{ }^{* *} p<0.01 ;{ }^{* * *} p<0.001$.

laboratory experiment we found that molar C:P ratios of natural seston with $62 \%$ detritus significantly decreased from 164 to 126. Additionally, a strong impact of phosphorus on growth is not necessarily causal as at low C:P levels phosphorus limitation cannot be expected. However, in two experiments, we found a simultaneous limitation by carbon and phosphorus, which shows that in addition to theoretical and laboratory studies (Sterner 1997, Boersma and Kreutzer 2002, Acharya et al. 2004) also in natural systems food quality effects can be observed even at low food concentrations.

For phosphorus an approximate threshold exists (phosphorus to carbon ratio) below which a mineral limitation for Daphnia growth can be expected. In contrast, no fatty acid to carbon threshold ratios are known (Becker and Boersma 2010, Brett 2010). Moreover, thresholds probably vary in nature depending on environmental conditions (Sperfeld and Wacker 2011). Compared to purely laboratory studies that found evidence for co-limitation of Daphnia (Lukas et al. 2011, Spenfeld et al. 2012), we have indications for such simultaneous limitations in nature. We observed a simultaneous limitation by food quantity and fatty acids when seston was supplemented with EPA containing liposomes in four experiments in August and September 2008. The growth rates of $D$. galeata were only slightly enhanced by EPA supplementation, which was in accordance with the theory that food quality effects decrease with decreasing food quantity (Hessen 1990, Sterner 1997) and confirmed that food quantity - food quality co-limitation indeed occurred in nature (Boersma et al. 2001, Park et al. 2003). We can exclude that the growth enhancement by EPA liposomes was simply based on an increased availability of carbon [fatty acids can serve as a carbon source for Daphnia (Boersma and Stelzer 2000, Plath and Boersma 2001)] because supplementations with ALA and EPA liposomes provided the same extra amount of carbon to the food suspension. Nevertheless, it is hardly possible to distinguish between the importance of EPA and ALA, because only during two of the four experiments with significant EPA effects growth rates on seston +EPA were significantly higher than on seston + ALA. This was also evident from the relative importance of EPA and ALA as predictors for growth of $D$. galeatd in 2008, which was quite similar in the multiple regression analysis. Both variables were present in one of the two best models according to AICc. However, both fatty acids belong to the family of omega-3 PUFAs, and at least underline the importance of this group as co-limiting factors for the growth of D. galeata in 2008 .

The negative deviations of some growth rates from growth on pure seston (although significant only in one case; Fig. 5) may have been caused by a dilution effect of the supplementations: On the one hand the addition of liposomes, buffer or algae suspensions increases the share of the supplemented compounds. On the other hand the share of other (i.e. not supplemented) potentially essential food components in the seston is simultaneously reduced, and might fall below a certain threshold and then become limiting.

Our results indicate that the growth of $D$. galeata was simultaneously constrained by food quantity and quality already in 1997 and thus the nutritional challenges the animals were exposed to were presumably more complex than previously assumed. Our multiple regression and model selection approach confirmed the interpretation by Wacker and von Elert (2001) that the growth of D. galeata in 1997 was constrained by a low availability of ALA. In addition, our approach revealed a carbon limitation of $D$. galeata in 1997, indicating a co-limitation by carbon and ALA. Hence, the multiple regression approach described here provided a powerful tool to identify nutritional challenges animals were exposed to in past years. Nevertheless, clear evidence for a limitation by a specific nutrient can be obtained only by increasing the availability of dietary nutrients experimentally, i.e. by supplementation. In 2008, we used a combination of both approaches to identify potentially limiting nutrients. The model selection approach showed that the growth of $D$. galeata was affected to some extent by all nutrients considered and the supplementation approach revealed seasonal changes in nutrient limitations and thus confirmed and complemented the first approach. 
Conclusively, oligotrophication of Lake Constance was associated with changes in the contribution of bacteria (as phosphorus source) and changes in the phytoplankton taxonomic composition (and thus changes in the availability of fatty acids), as well as an overall decrease of food quantity, which resulted in seasonally varying co-limitations of D. galeata. It appears that seasonal and anthropogenically induced annual changes in nutrient availabilities can create complex limitation scenarios consumers have to cope with.

Acknowledgements - We thank S. Donath, C. Gebauer, S. Heim, P. Mahler, G. Richter and P. Merkel for excellent technical assistance, U. Gaedke, R. Gergs, E. Sperfeld and M. Vos for comments on earlier drafts of the manuscript, and J. Urabe for constructive comments. Abundance data of Daphnia galeata were kindly provided by D. Straile. This study was supported by the German Research Foundation (DFG RO 1008/12-1 and WA 2445/4-1).

\section{References}

Acharya, A. et al. 2004. Effects of stoichiometric dietary mixing on Daphnia growth and reproduction. - Oecologia 138: 333-340.

Ahlgren, G. et al. 1990. Lipid composition and food quality for some freshwater phytoplankton for cladoceran zooplankters. - J. Plankton Res. 12: 809-818.

Anneville, O. et al. 2005. Phosphorus decrease and climate variability: mediators of synchrony in phytoplankton changes among European peri-alpine lakes. - Freshwater Biol. 50: $1731-1746$.

Anneville, O. et al. 2004. Seasonal and inter-annual scales of variability in phytoplankton assemblages: comparison of phytoplankton dynamics in three peri-alpine lakes over a period of 28 years. - Freshwater Biol. 49: 98-115.

Becker, C. and Boersma, M. 2010. Limiting levels of eicosapentaenoic acid: what do we really know? - Limnol. Oceanogr. 55: 459-462.

Beenakkers, A. M. T. et al. 1985. Insect lipids and lipoproteins, and their physiological processes. - Prog. Lipid Res. 24: 19-67.

Boersma, M. and Stelzer, C.-P. 2000. Response of a zooplankton community to the addition of unsaturated fatty acids: an enclosure study. - Freshwater Biol. 45: 179-188.

Boersma, M. and Kreutzer, C. 2002. Life at the edge: is food quality really of minor importance at low quantities? - Ecology 83: 2552-2561.

Boersma, M. et al. 2001. Nutritional quality of seston for the freshwater herbivore Daphnia galeata $x$ byalina: biochemical versus mineral limitations. - Oecologia 129: 342-348.

Brett, M. T. 2010. Is a low EPA growth saturation threshold supported by the data presented in Becker and Boersma (2005)? - Limnol. Oceanogr. 55: 455-458.

Brett, M. T. et al. 2000. Empirical analysis of the effect of phosphorus limitation on algal food quality for freshwater zooplankton. - Limnol. Oceanogr. 45: 1564-1575.

Burnham, K. P. and Anderson, D. R. 1998. Model selection and inference - a practical information-theoretic approach. - Springer.

Burns, C. W. 1968. The relationship of body size of filterfeeding Cladocera and the maximum size of particles ingested. - Limnol. Oceanogr. 13: 675-678.

DeMort, W. R. and Müller-Navarra, D. C. 1997. The importance of highly unsaturated fatty acids in zooplankton nutrition: evidence from experiments with Daphnia, a cyanobacterium and lipid emulsions. - Freshwater Biol. 38: 649-664.
Dokulil, M. T. and Teubner, K. 2005. Do phytoplankton communities correctly track trophic changes? An assessment using directly measured and paleolimnological data. - Freshwater Biol. 50: 1594-1604.

Elser, J. J. et al. 2001. Nutrient limitation reduces food quality for zooplankton: Daphnia response to seston phosphorus enrichment. - Ecology 82: 898-903.

Elser, J. J. et al. 2002. Effects of light and nutrients on plankton stoichiometry and biomass in a P-limited lake. - Hydrobiologia 481: 101-112.

Elser, J. J. et al. 2003. Growth rate-stoichiometry couplings in diverse biota. - Ecol. Lett. 6: 936-943.

Gaedke, U. 1992. The size distribution of plankton biomass in a large lake and its seasonal variability. - Limnol. Oceanogr. 37: $1202-1220$

Gaedke, U. et al. 2002. Interplay between energy limitation and nutritional deficiency: empirical data and food web models. - Ecol. Monogr. 72: 251-270.

Gladyshev, M. I. et al. 2006. Influence of sestonic elemental and essential fatty acid contents in a eutrophic reservoir in Siberia on population growth of Daphnia (longispina group). - J. Plankton Res. 28: 907-917.

Gladyshev, M. I. et al. 2008. Growth rate of Daphnia feeding on seston in a Siberian reservoir: the role of essential fatty acid. - Aqquat. Ecol. 42: 617-627.

Greenberg, A. E. et al. (eds) 1985. Standard methods for the examination of water and wastewater. - Am. Public Health Ass.

Hessen, D. O. 1990. Carbon, nitrogen and phosphorus status in Daphnia at varying food conditions. - J. Plankton Res. 12: 1239-1249.

Hessen, D. O. 2006. Determinants of seston C:P-ration in lakes. - Freshwater Biol. 51: 1560-1569.

Hessen, D. O. and Anderson, T. R. 2008. Excess carbon in aquatic organism and ecosystems: physiological, ecological, and evolutionary implications. - Limnol. Oceanogr. 53: 1685-1696.

Jeppesen, E. et al. 2005. Lake responses to reduced nutrient loading - an analysis of contemporary long-term data from 35 case studies. - Freshwater Biol. 50: 1747-1771.

Johnson, J. B. and Omland, K. S. 2004. Model selection in ecology and evolution. - Trends Ecol. Evol. 19: 101-108.

Jüttner, F. et al. 1983. Environmental factors affecting the formation of mesotyloxid, dimethylallylic alcohol and other volatile compounds excreted by Anabaena cylindrica. - J. Gen. Microbiol. 129: 407-412.

Kainz, M. J. et al. 2009. Essential fatty acid concentrations of different seston sizes and zooplankton: a field study of monomictic coastal lakes. - J. Plankton Res. 31: 635-645.

Kamjunke, N. et al. 1999. Bacteria ingestion by Daphnia galeata in a biomanipulated reservoir: a mechanism stabilizing biomanipulation? - Hydrobiologia 403: 109-121.

Katechakis, A. et al. 2005. Mixotrophic versus photoautotrophic specialist algae as food for zooplankton: the light:nutrient hypothesis might not hold for mixotrophs. - Limnol. Oceanogr. 50: 1290-1299.

Lampert, W. and Sommer, U. 1997. Limnoecology: the ecology of lakes and streams. -- Oxford Univ. Press.

Leeper, D. A. and Porter, K. G. 1995. Toxicity of mixotrophic chrysophyte Proterioochromonas malhamensis to the cladoceran Daphnia magna. - Arch. Hydrobiol. 134: 207-222.

Lukas, M. et al. 2011. Growth rate hypothesis does not apply across colimiting conditions: cholesterol limitation affects phosphorus homeostasis of an aquatic herbivore. - Funct. Ecol. 25: 1206-1214.

Martin-Creuzburg, D. et al. 2008. Nutritional constraints at the cyanobacteria-Dapbnia magna interface: the role of sterols. - Limnol. Oceanogr. 53: 456-468. 
Mehner, T. et al. 2002. Biomanipulation of lake ecosystems: successful applications and expanding complexity in the underlying science. - Freshwater Biol. 47: 2453-2465.

Müller-Navarra, D. C. 1995. Evicence that a highly unsaturated fatty acid limits Daphnia growth in nature. - Arch. Hydrobiol 132: 297-307.

Müller-Navarra, D. C. and Lampert, W. 1996. Seasonal patterns of food limitation in Daphnia galeata: seperating food quantity and food quality effects. - J. Plankton Res. 18: 1137-1157.

Müller-Navarra, D. C. et al. 2000. A highly unsaturated fatty acid predicts carbon transfer between primary producers and consumers. - Nature 403: 74-77.

Olsen, Y. et al. 1986. Dependence of the rate of release of phosphorus by zooplankton on the P:C ratio in the food supply, as calculated by a recycling model. - Limnol. Oceanogr. 31: 34-44.

Park, S. et al. 2003. Seston food quality and Daphnia production effeciencies in an oligo-mesotrophic subalpine lake. - Aquat. Ecol. 37: 123-136.

Piepho, M. et al. Species-specific variation in fatty acids concentrations of four phytoplankton species: does phosphorus supply influence the effect of light intensity or temperature? - J. Phycol. doi: 10.1111/j.1529-8817.2011.01103.x

Plath, K. and Boersma, M. 2001. Mineral limitation of zooplankton: stoichiometric constraints and optimal foraging. - Ecology 82: 1260-1269.

Porter, K. G. and Feig, Y. S. 1980. The use of DAPI for identifying and counting aquatic microflora. - Limnol. Oceanogr. 25: 943-948.

Ravet, J. L. et al. 2003. A test of the role of polyunsaturated fatty acids in phytoplankton food quality for Daphnia using liposome supplementation. - Limnol. Oceanogr. 48: 1938-1947.

Rellstab, C. et al. 2007. Temporary collapse of the Daphnia population in turbid and ultra-oligotrophic Lake Brienz. - Aquat. Sci. 69: 257-270.

Rothhaupt, K. O. 1995. Algal nutrient limitation affects rotifer growth rate but not ingestion rate. - Limnol. Oceanogr. 40: $1201-1208$

Seebens, H. et al. 2009. Copepod life cycle adaptations and success in response to phytoplankton spring bloom phenology. - Global Change Biol. 15: 1394-1404.

Sherr, E. and Sherr, B. 1988. Role of microbes in pelagic food webs: a revised concept. - Limnol. Oceanogr. 33: 1225-1227.

Sommer, U. (ed.) 1989. Plankton ecology: succession in plankton communities. - Springer.

Sperfeld, E. and Wacker, A. 2011. Temperature and cholesterol induced changes in eicosapentaenoic acid limitation of Daphnia magna determined by a promising method to estimate growth saturation thresholds. - Limnol. Oceanogr. 56: 1273-1284.

Sperfeld et al. 2012. Multiple resource limitation theory applied to herbivorous consumers: Liebig's minimum rule vs. inter- active co-limitation. - Ecol. Lett. doi: 10.1111/j.1461-0248. 2011.01719.x.

Sterner, R. W. 1997. Modelling interactions of food quality and quantity in homeostatic consumers. - Freshwater Biol. 38: 473-481.

Sterner, R. W. and Hessen, D. O. 1994. Algal nutrient limitation and the nutrition of aquatic herbivores. - Annu. Rev. Ecol. Syst. 25: 1-29.

Sterner, R. W. et al. 1993. Phytoplankton nutrient limitation and food quality for Daphnia. - Limnol. Oceanogr. 38: 857-871.

Sterner, R. W. et al. 2008. Scale-dependent carbon: nitrogen: phosphorus seston stoichiometry in marine and freshwaters. - Limnol. Oceanogr. 53: 1169-1180.

Stich, H. B. and Lampert, W. 1981. Predator evasion as an explanation of diurnal vertical migration by zooplankton. - Nature 293: 396-398.

Stich, H. B. and Lampert, W. 1984. Growth and reproduction of migrating and non-migrating Daphnia species under simulated food and temperature conditions of diurnal vertical migration. - Oecologia 61: 192-196.

Stich, H. B. and Brinker, A. 2010. Oligotrophication outweighs effects of global warming in a large, deep, stratified lake ecosystem. - Global Change Biol. 16: 877-888.

Straile, D. and Geller, W. 1998. Crustacean zooplankton in Lake Constance from 1920 to 1995: response to eutrophication and re-oligotrophication. - Adv. Limnol. 53: 255-274.

Thompson, P. A. et al. 1990. Influence of irradiance on the fatty acid composition of phytoplankton. - J. Phycol. 26: 278-288.

Urabe, J. and Watanabe, Y. 1992. Possibility of $\mathrm{N}$ or P limitation for planktonic cladocerans: an experimental test. - Limnol. Oceanogr. 37: 244-251.

Urabe, J. et al. 1997. Phosphorus limitation of Daphnia growth: is it real? - Limnol. Oceanogr. 42: 1436-1443.

Vadstein, O. et al. 1993. The role of planktonic bacteria in phosphorus cycling in lakes - sink and link. - Limnol. Oceanogr. 38: 1539-1544.

Van Donk, E. et al. 2008. Re-oligotrophication by phosphorus reduction and effects on seston quality in lakes. - Limnologica 38: 189-202.

Von Elert, E. 2002. Determination of limiting polyunsaturated fatty acids in Daphnia galeata using a new method to enrich food algae with single fatty acids. - Limnol. Oceanogr. 47: $1764-1773$.

Wacker, A. and Von Elert, E. 2001. Polyunsaturated fatty acids: evidence for non-substitutable biochemical resources in Daphnia galeata. - Ecology 82: 2507-2520.

Wacker, A. and Martin-Creuzburg, D. 2007. Allocation of essential lipids in Daphnia magna during exposure to poor food quality. - Funct. Ecol. 21: 738-747.

Wacker, A. and Weithoff, G. 2009. Carbon assimilation mode in mixotrophs and the fatty acid composition of their rotifer consumers. - Freshwater Biol. 54: 2189-2199. 